\title{
Effects of Acute Tryptophan Depletion on Negative Symptoms and Smoking Topography in Nicotine-Dependent Schizophrenics and Nonpsychiatric Controls
}

\author{
Brian Hitsman*,', Bonnie Spring ${ }^{2,3}$, William Wolf ${ }^{3,4}$, Regina Pingitore ${ }^{2,3}$, John W Crayton ${ }^{3,5}$ and \\ Donald Hedeker ${ }^{6}$ \\ 'Centers for Behavioral and Preventive Medicine, Brown Medical School and The Miriam Hospital, Providence, RI, USA; ${ }^{2}$ Department of \\ Psychology, University of Illinois at Chicago, Chicago, IL, USA; ${ }^{3}$ Biological Psychiatry Section, Hines VA Hospital, Hines, IL, USA; ${ }^{4}$ Department of \\ Pharmacology, Loyola University School of Medicine, USA; ${ }^{5}$ Department of Psychiatry, Loyola University School of Medicine, USA; ${ }^{6}$ School of Public \\ Health, University of Illinois at Chicago, Chicago, IL, USA
}

\begin{abstract}
We studied the effect of acute tryptophan depletion (ATD), which transiently reduces brain serotonin, on negative symptoms and cigarette smoking topography in schizophrenic smokers. Nicotine-dependent schizophrenics $(n=1 \mathrm{I})$ and nonpsychiatric controls $(n=8)$ were examined after ingesting comparable mixtures that do and do not deplete plasma tryptophan. Tryptophan-depleting and placebo mixtures were administered double-blind and in counterbalanced order. Conditions were separated by a I-week interval. Psychopathologic symptoms (negative symptoms, depression) and smoking topography (time to first puff, number of puffs per cigarette, puff duration, interpuff interval, cigarette duration, and percentage of cigarette smoked) were measured before ingestion and again beginning $5 \mathrm{~h}$ after each mixture, corresponding to the time of maximal tryptophan depletion. Analyses were conducted using repeated measures analyses of variance (psychopathologic symptoms) and analyses of covariance (smoking topography) controlling for cigarette length. We found that ATD influenced smoking topography in both schizophrenics and nonpsychiatric controls in a manner suggestive of increased desire to smoke. Schizophrenics exhibited increased puff duration and decreased cigarette duration. Controls displayed increased puff duration. ATD did not produce changes in negative symptoms or depression. Compromising brain serotonin via ATD appears to intensify smoking behavior in nicotine-dependent individuals directly, rather than indirectly through changes in either mood or psychopathologic symptoms.

Neuropsychopharmacology (2005) 30, 640-648, advance online publication, 12 January 2005; doi: I 0. I 038/s..npp. 130065 I
\end{abstract}

Keywords: tryptophan; smoking; nicotine; serotonin; motivation; schizophrenia

\section{INTRODUCTION}

Approximately $1 \%$ of the US population is diagnosed with schizophrenia (American Psychiatric Association, 1994) and at least $70 \%$ of these individuals smoke cigarettes regularly (De Leon et al, 1995). Schizophrenics smoke more heavily, use higher tar- and nicotine-containing cigarettes, and have longer smoking histories than nonpsychiatric smokers (Hughes et al, 1986; O’Farrell et al, 1983). Even after controlling for amount smoked, smokers with schizophrenia have higher cotinine levels than smokers without

\footnotetext{
*Correspondence: Dr B Hitsman, The Miriam Hospital, Centers for Behavioral and Preventive Medicine, Coro Building, Suite 500, I Hoppin Street, Providence, RI 02903, USA, Tel: + I 4017938018 , Fax: + I 401793 8078; E-mail: Brian_Hitsman@Brown.edu

Received 4 February 2004; revised 10 April 2004; accepted 25 October 2004

Online publication: 16 November 2004 at http://www.acnp.org/citations /NPPI | | 604040052/default.pdf
}

schizophrenia (Olincy et al, 1997). Patients' higher levels may be attributable to a combination of their greater use of higher nicotine yield cigarettes and a smoking topography that maximizes nicotine intake (eg increased number of puffs per cigarette). One contributor to the high prevalence of smoking and nicotine dependence among schizophrenics may be that smoking is reinforced via nicotine's ability to influence several neurotransmitters that are dysregulated in schizophrenia (Dalack et al, 1998; McChargue et al, 2002).

Considerable evidence suggests involvement of a serotonergic dysfunction in schizophrenia, especially with respect to negative symptoms (Lieberman et al, 1998). Among schizophrenics with co-occurring nicotine dependence, serotonergic dysregulation also has been linked to the amount of smoking and to success in quitting smoking. In two studies (George et al, 1995; McEvoy et al, 1995), smoking decreased significantly when schizophrenics were switched from traditional antipsychotics (eg haloperidol) to the atypical antipsychotic, clozapine. When attempting to 
quit smoking, schizophrenics treated with atypicals appear to achieve better quit rates than those on traditional agents (George et al, 2000). Unlike traditionals, which antagonize only dopamine receptors, atypicals antagonize serotonin and dopamine receptors and improve negative as well as positive symptoms (Meltzer et al, 2003).

In the current study, we used acute tryptophan depletion (ATD), a dietary manipulation that decreases brain serotonin acutely (Delgado et al, 1990; Nishizawa et al, 1997) to examine serotonergic involvement in negative symptoms and smoking topography among nicotinedependent schizophrenics. We hypothesized that ATD, analogous to atypical antipsychotics that antagonize serotonergic neurotransmission, would reduce negative symptoms and decrease urge to smoke. Decreased urge to smoke would be reflected in increased time to first puff, interpuff interval, and cigarette duration, and decreased puffs per cigarette, puff duration, and amount of cigarette smoked. Nonpsychiatric smokers, in contrast, were not expected to show any appreciable changes in urge to smoke as a function of ATD.

\section{METHODS}

\section{Participants}

We studied 19 smokers: 11 schizophrenics and eight controls with neither a personal nor a familial history of psychiatric illness. All participants met the DSM-IV criteria for nicotine dependence. Schizophrenics had a DSM-IV diagnosis of schizophrenia $(n=7)$ or schizoaffective disorder $(n=4)$. Table 1 displays their type and dose of antipsychotic medication.

Study inclusion criteria delineated strict requirements regarding psychotropic medications. Schizophrenics were required to be medication stable (same antipsychotic medication and dosage $\geqslant 2$ months) and treated with either a traditional (eg haloperidol) or an atypical antipsychotic (eg clozapine). All patients were required to be treated on an outpatient basis. They could not be taking antidepressant or mood-stabilizing agents. Given the focus on schizophrenia and negative symptoms, we attempted to recruit

Table I Patient Study Diagnosis and Antipsychotic Medications

\begin{tabular}{|c|c|c|}
\hline $\begin{array}{l}\text { Patient no.l } \\
\text { gender/age }\end{array}$ & $\begin{array}{l}\text { Primary } \\
\text { diagnosis }\end{array}$ & $\begin{array}{l}\text { Medication/dose } \\
\text { (mg/day) }\end{array}$ \\
\hline I/M/47 & Schizoaffective & Clozapine 600 \\
\hline $2 / M / 61$ & Schizophrenia ${ }^{a}$ & Haloperidol deconoate 50 \\
\hline 5/M4I & Schizoaffective & Olanzapine 20 \\
\hline 6/M/45 & Schizophrenia & Clozapine 600 \\
\hline I0/M/44 & Schizoaffective & Risperidone 6 \\
\hline | | /M/39 & Schizophrenia & Olanzapine 20 \\
\hline |3/M/46 & Schizophrenia & Clozapine 550 \\
\hline$|4 / M / 4|$ & Schizophrenia & Risperidone 5 \\
\hline |5/F/47 & Schizophrenia & Risperidone 6 \\
\hline $16 / M / 26$ & Schizoaffective & Clozapine 200 \\
\hline I8/M/36 & Schizophrenia & Olanzapine 15 \\
\hline
\end{tabular}

anly patient with no lifetime history of substance abuse or dependence. patients with prominent negative symptoms. Controls could not be taking medications (antidepressant or antianxiety agents) or herbal supplements (eg St John's Wort) known to affect mood.

Study candidates were excluded from participation if they acknowledged during telephone screening that they were pregnant or lactating, had a history of food allergies, were using nicotine replacement or other smoking pharmacotherapy (eg bupropion), or had received alcohol or drug abuse treatment within the last year. Also excluded were candidates whose physical examination or blood testing revealed that they were greater than 60 pounds overweight or had an unstable medical condition (eg diabetes). Finally, individuals were not permitted to enroll if it was established through structured interview or chart review (for schizophrenic or schizoaffective patients) that they had a substance use disorder other than nicotine dependence. This research was approved by the Institutional Review Boards of the Hines VA and Miriam Hospitals. Participants were paid $\$ 100.00$ for completing all aspects of the study.

\section{Measures}

Structured clinical interview for DSM-IV (SCID-IV). The SCID-IV (Williams et al, 1992) was used to assess demographic information and Axis I psychopathology. Given that this study concerned the comorbidity between nicotine dependence and schizophrenia, only the modules for the psychotic, mood, anxiety, and substance use disorders were administered. Satisfactory reliability data for these diagnoses have been reported and the SCID compares favorably with other diagnostic assessment methods (Williams et al, 1992).

Negative symptoms. To measure negative symptoms, we administered the Positive and Negative Syndrome Scale (PANSS), a structured interview developed by Kay et al (1987). Only the negative symptom subscale was used, which includes seven negative symptoms rated from 7 to 49 , with higher scores reflecting greater symptomatology.

Modified Hamilton Depression Rating Scale (MHAMD). We used a modified version of the 21-item Hamilton Depression Scale (Hamilton, 1967). The MHAMD includes nine items that Delgado et al (1991) found sensitive to ATD: low energy, depressed mood, feelings of guilt, decreased concentration and motor activity, anxious mood, decreased appetite, loss of pleasure, feelings of worthlessness, and loss of interest. Scores on the MHAMD range from 0 to 32 with higher scores indicating greater symptomatology.

Smoking topography. The influence of ATD on smoking behavior was measured via the following topography variables: time to first puff, number of puffs per cigarette, puff duration, interpuff interval, cigarette duration, and percentage of cigarette smoked. Acute changes in smoking topography and other drug consummatory behaviors have been found to reflect changes in drug motivation (Davidson et al, 1999; Renkin et al, 1979).

Topography data were obtained by hand-timing the smoking behavior of participants who had been videotaped 
while smoking. Scoring was performed prior to breaking the randomization blind. The smoking topography variables were operationalized as follows. Latency to first puff equaled the time in seconds that elapsed between when the participant was handed the cigarettes, ashtray, and lighter and when the lit cigarette came in contact with participant's lips. Puff frequency equaled the number of times a lit cigarette came in contact with the participant's lips. Puff duration equaled the time in seconds that a lit cigarette was in contact with the smoker's lips (breaking of the contact terminated a puff). For participants who held the cigarette with the mouth, as opposed to holding it with the hand, puff duration equaled the time in seconds that the tobacco burned while in contact with the lips (ceasing of the burn terminated the puff). Interpuff interval equaled the time in seconds from the termination of one puff until the beginning of the next puff. Cigarette duration equaled the time in seconds that elapsed between lighting the cigarette and extinguishing it. The percentage of cigarette smoked was determined by retrieving each cigarette butt, measuring its length, and subtracting that value from the length of the unsmoked cigarette (in $\mathrm{cm}$ ). The length of cigarette burned was then divided by the initial length of the cigarette to yield the percentage of cigarette smoked.

Reliability of the smoking topography ratings was evaluated by rescoring of participants' baseline assessment during the placebo challenge condition. Reliability coefficients were calculated to compare the agreement between the two sets of topography ratings. Results showed that there was excellent reliability across variables, with alphas $>0.90$.

Nicotine withdrawal. Symptoms of nicotine withdrawal were assessed using a 7-item version of the Minnesota Tobacco Withdrawal Scale (MTWS; Hughes and Hatsukami, 1986). Using a four-point scale $(0=$ no problem, $1=$ mild problem, $2=$ moderate problem, and $3=$ severe problem), participants rated seven withdrawal symptoms (depressed mood, anger, irritability or frustration, anxiety or nervousness, restlessness or impatience, difficulty concentrating, and increased appetite or hunger). A total score was computed by summing the seven items. Scores could range from 0 to 21 . The MTWS was given to assess and rule out a possible confounding influence of nicotine withdrawal on smoking topography, mood, or psychiatric symptoms.

\section{Procedure}

Initial screening. Candidates who responded to recruitment were screened over the telephone. They were told that two 8 -h sessions were required 'to determine whether smokers experience changes in mood and cigarette smoking after drinking an amino-acid beverage'. Interested candidates were given questionnaires to assess their smoking and health history. An initial appointment was scheduled for those eligible, during which details of the study were explained and participants gave written informed consent. Participants also provided a urine sample that was assayed to test for recent drug use. Then, participants were seen for a physical exam during which their responses to the medical history questionnaire were reviewed.
Screening phase assessments. Participants who met medical eligibility requirements underwent psychiatric screening. Lifetime history of psychopathology, including nicotine dependence, was assessed using the SCID-IV. For schizophrenics, diagnoses were confirmed via review of clinical data presented in their medical chart. The Fagerstrom Tolerance Questionnaire (Fagerstrom, 1978) was administered to measure the degree of nicotine dependence. Other screening measures included the Beck Depression Inventory (Beck et al, 1961), the Hamilton Depression Scale, and the negative symptom scale of the PANSS. Finally, participants recorded their use of cigarettes and caffeine-containing beverages for a 48 - $h$ period. This provided a benchmark average daily intake against which to compare cigarette and caffeine consumption during the two conditions to ensure that intake remained comparable. Study candidates who satisfied the screening criteria were scheduled for testing.

Experimental protocol. Participants received the ATD and placebo mixtures on different test days, which were separated by a 1-week interval. Mixtures were administered double-blind and in counterbalanced order. Females were tested between days 7 and 21 of their menstrual cycle. At 3 days prior to each session, those schizophrenic or schizoaffective patients who typically took their psychiatric medications in the morning switched to an evening dose.

For each session, participants arrived at the laboratory by 0800 after an overnight fast. They provided a urine sample to screen for alcohol and illicit drug use and underwent baseline assessment of psychopathologic symptoms and smoking topography. Participants' smoking was videotaped to permit later scoring of topography. In order to minimize reactivity due to the participants' awareness of being videotaped, the camera was not easily visible. Debriefing interviews confirmed that this assessment procedure was unobtrusive.

At 0930, participants ingested one of two mixtures. The ATD mixture consisted of the following 15 amino acids: L-alanine $(5.5 \mathrm{~g})$, L-arginine $(4.9 \mathrm{~g})$, L-cystine $(2.7 \mathrm{~g})$, glycine (3.2 g), L-histidine (3.2 g), L-isoleucine (8.0 g), L-leucine $(13.5 \mathrm{~g})$, L-lysine mono-hydrochloride $(11.0 \mathrm{~g})$, L-methionine (3.0 g), L-phenylalanine $(5.7 \mathrm{~g})$, L-proline $(12.2 \mathrm{~g})$, L-serine $(6.9 \mathrm{~g})$, L-threonine $(6.9 \mathrm{~g})$, L-tyrosine $(6.9 \mathrm{~g})$, and L-valine $(8.9 \mathrm{~g})$. Three amino acids, methionine, cystine, and arginine, were encapsulated because their unpalatable taste could not be masked by chocolate and peppermint. The remaining amino acids were mixed with $\frac{1}{3}$ cup tonic water, four drops peppermint extract (added using dropping pippet), one tablespoon Hershey's chocolate syrup, and five small ice cubes. In the placebo condition, participants ingested identical capsules containing confectioner's sugar. This was followed by the placebo mixture consisting of $\frac{5}{6}$ cup tonic water, five drops peppermint extract (added using dropping pippet), one tablespoon Hershey's chocolate syrup, two tablespoon baking soda, one tablespoon unflavored Metamucil, and seven small ice cubes.

Breakfast, lunch, and mid-day snack foods from the lowtryptophan diet used by Delgado et al (1990) were provided on each test day. Nicotine and caffeine intake were standardized in order to ensure comparability between conditions and to reduce the likelihood that neither nicotine 
nor caffeine withdrawal would be mistaken for psychopathologic symptoms (Hughes and Howard, 1997). Participants were permitted to smoke their brand of cigarettes at regular intervals until about 1415 . Beginning at 0800 , expired carbon monoxide readings were taken hourly to confirm that participants were smoking at their usual rates. From 1415 until the postdepletion assessment was completed (approximately 1600), participants refrained from smoking or drinking coffee. This period of deprivation (105 min) was chosen to maximize participants' desire to smoke, yet not invoke symptoms of nicotine withdrawal.

The postdepletion reassessment of psychopathologic symptoms (negative symptoms, depression) and nicotine withdrawal began at 1430 ( $5 \mathrm{~h}$ after mixture ingestion), which corresponded to the time of maximal tryptophan depletion (Delgado et al, 1990). Nicotine withdrawal was rated last in order to capture the level of withdrawal just prior to the assessment of smoking topography. Immediately following the measurement battery (1600), topography was assessed. The procedure began by handing participants their pack of cigarettes, along with a lighter and astray, and announcing a $30 \mathrm{~min}$ wait before their dinner. Participants were then informed that they would be permitted to smoke during the waiting period so long as they remained seated in the observation room. At 1630, after the assessment had been completed, participants were served a nutritionally balanced dinner that repleted tryptophan. The Hamilton Depression Scale was readministered prior to the participant leaving the laboratory in order to assess severity of depressive symptoms. Table 2 provides an overview of the protocol sequence. Our two prior studies of ATD $(N=79)$ involving identical procedures resulted in greater than $90 \%$ reduction in the ratio of plasma tryptophan to other large neutral amino acids (tyrosine, valine, phenylalanine, isoleucine, leucine) (Pergadia et al, 2004; Spring et al, 1997).

\section{Statistical Analyses}

We compared schizophrenics and nonpsychiatric controls on baseline demographic, smoking, and mood variables using $t$-tests for continuous variables and $\chi^{2}$ analyses for categorical ones. Next, we used univariate repeated measures analyses of variance to examine the effect of ATD on change in psychopathologic symptoms (negative

Table 2 Summary of the Protocol Sequence

\begin{tabular}{|c|c|}
\hline Time & Procedure \\
\hline 0830 & $\begin{array}{l}\text { Drug and alcohol screen; baseline assessments of } \\
\text { psychopathologic symptoms and smoking topography }\end{array}$ \\
\hline 0930 & Consumption of amino-acid or placebo mixture \\
\hline 1415 & Participant refrained from smoking until 1600 \\
\hline 1430 & $\begin{array}{l}\text { Approximate time of maximal tryptophan depletion; } \\
\text { readministration of baseline assessments; assessment of nicotine } \\
\text { withdrawal }\end{array}$ \\
\hline 1600 & Smoking topography reassessment (30 min session) \\
\hline 1630 & $\begin{array}{l}\text { Participant served a nutritionally balanced dinner; } \\
\text { psychopathologic symptoms reassessed }\end{array}$ \\
\hline
\end{tabular}

symptoms, depression) among schizophrenics and controls. The analysis of the smoking topography variables (time to first puff, puff duration, interpuff interval, number of puffs per cigarette, cigarette duration, and percentage of cigarette smoked) was conducted using univariate repeated measures analyses of covariance (ANCOVA). The covariate was length of cigarette (in $\mathrm{cm}$ ). All analyses involved condition (ATD/ placebo) and time (pre/postmixture) as within-subject factors and psychiatric diagnosis (schizophrenic/nonpsychiatric control) as a between-subjects factor. In both sets of univariate analyses (psychopathologic symptoms, smoking topography), statistically significant interaction effects among diagnosis, condition, and time were decomposed with simple main effects analyses (for two-way interactions) and simple interaction effects analyses (for three-way interactions).

\section{RESULTS}

\section{Subject Characteristics}

Table 3 displays demographic and baseline smoking and symptom characteristics for schizophrenics and controls. Participants were mostly Caucasian (79\%), with a mean age of $39(\mathrm{SD}=12.9)$ years. Compared to controls, schizophrenics smoked significantly more cigarettes per day and exhibited higher expired carbon monoxide levels. They also displayed a greater degree of nicotine dependence, as indicated by their Fagerstrom scores. Schizophrenics had significantly higher negative symptom and depression scores than did controls. Of 11 schizophrenics, 10 were treated with atypical antipsychotics and had a history of substance abuse or dependence. None of the controls had a history of substance abuse or dependence.

\section{Psychopathologic Symptoms}

We hypothesized that ATD, as compared to placebo, would worsen negative symptoms for schizophrenics, but not for

Table 3 Demographic, Smoking and Psychopathological Characteristics (Mean and SD) for Schizophrenics and Controls

\begin{tabular}{lccc}
\hline Variable & $\begin{array}{c}\text { Schizophrenics } \\
(\mathbf{n}=\mathbf{I} \mathbf{)})\end{array}$ & $\begin{array}{c}\text { Controls } \\
(\mathbf{n}=\mathbf{8})\end{array}$ & $\mathbf{p}$ \\
\hline Age (in years) & $43.0(8.6)$ & $35.5(16.9)$ & 0.22 \\
Gender (\% male) & $91 \%$ & $50 \%$ & 0.04 \\
Ethnicity (\% Caucasian) & $73 \%$ & $88 \%$ & 0.44 \\
Education (\% ₹high school) & $64 \%$ & $100 \%$ & 0.06 \\
Cigarettes/day & $27.3(11.7)$ & $18.8(2.3)$ & 0.04 \\
Carbon monoxide level & $30.6(11.0)$ & $19.1(6.0)$ & 0.01 \\
Nicotine content of cigarette & $1.1(0.3)$ & $0.8(0.3)$ & 0.08 \\
Number of years smoked & $27.6(11.4)$ & $17.8(16.3)$ & 0.17 \\
Lifetime quit attempts & $1.9(2.2)$ & $2.4(2.4)$ & 0.67 \\
Fagerstrom Tolerance Questionnaire & $7.5(1.4)$ & $5.6(1.7)$ & 0.02 \\
Hamilton Depression Scale & $7.2(2.2)$ & $2.1(2.1)$ & 0.00 \\
Beck Depression Inventory & $12.3(5.4)$ & $8.3(7.8)$ & 0.23 \\
PANSS Negative Symptom subscale & $16.4(4.0)$ & $7.5(0.8)$ & 0.00 \\
\hline
\end{tabular}


controls. On the contrary, the time $\times$ condition $\times$ group interaction for PANSS negative symptom scores was nonsignificant, $\mathrm{F}(1,17)=1.3, p=0.27$. There were, however, significant main effects of diagnosis, $\mathrm{F}(1,17)=41.6, p<0.01$, and time, $\mathrm{F}(1,17)=4.8, p=0.04$. Negative symptom scores were higher overall for schizophrenics $(M=16.8, \mathrm{SD}=0.9)$ than nonpsychiatric controls $(M=7.5, \mathrm{SD}=1.1)$, and were lower at $5 \mathrm{~h}(M=11.9, \mathrm{SD}=0.7)$ than at baseline $(M=12.4$, $S D=0.8)$. Mean change scores ( $5 \mathrm{~h}$ minus baseline) presented in Table 4 show the modest decrease in negative symptom severity over the course of the test days. Analysis of HAMD scores yielded a similar pattern of results.

\section{Smoking Topography}

Participants were first compared on the number of cigarettes smoked during each of the 30-min topography assessments, since any differences in cigarette intake between conditions could potentially confound the analysis of smoking topography. Results showed no statistically significant differences between conditions, $F(1,17)=1.2$, $p=0.30$. Overall, participants smoked a mean of 2.4 $(\mathrm{SD}=1.1)$ cigarettes during ATD and $2.5(\mathrm{SD}=1.2)$ during placebo. Schizophrenics smoked a mean of $2.6(\mathrm{SD}=1.4)$ during ATD and $2.8(\mathrm{SD}=1.4)$ during placebo. Controls smoked a mean of $2.0(\mathrm{SD}=0.5)$ during $\mathrm{ATD}$ and 2.1 $(\mathrm{SD}=0.6)$ during placebo.

Next, participants' level of nicotine withdrawal was compared across the groups and conditions to confirm that no differences in nicotine withdrawal had arisen during the $105 \mathrm{~min}$ abstinence period prior to the topography assessment. As hoped, there were no statistically significant differences in nicotine-withdrawal symptoms as a function

Table 4 Mean $( \pm S D)$ Change from Baseline to $5 \mathrm{~h}$ in Psychopathologic Symptoms as a Function of Psychiatric Diagnosis and Amino-Acid Condition

\begin{tabular}{|c|c|c|c|c|c|c|}
\hline \multirow[b]{3}{*}{ Group } & \multicolumn{6}{|c|}{ Condition } \\
\hline & \multicolumn{3}{|c|}{ Placebo } & \multicolumn{3}{|c|}{ Amino acid } \\
\hline & Baseline & $\mathbf{5} \mathbf{h}$ & $\Delta$ & Baseline & $5 \mathrm{~h}$ & $\Delta$ \\
\hline \multicolumn{7}{|c|}{ PANSS negative symptoms } \\
\hline \multirow[t]{2}{*}{ Schizophrenia } & 16.7 & 16.5 & -0.5 & 17.9 & 16.3 & -1.6 \\
\hline & $(4.3)$ & $(4.1)$ & $(2.1)$ & $(4.3)$ & $(4.1)$ & (2.3) \\
\hline \multirow[t]{2}{*}{ Control } & 7.5 & 7.4 & 0.0 & 7.8 & 7.5 & -0.3 \\
\hline & $(0.8)$ & $(0.5)$ & $(0.8)$ & $(1.2)$ & $(0.5)$ & $(1.3)$ \\
\hline \multicolumn{7}{|c|}{ Depression (MHAMD) } \\
\hline \multirow[t]{2}{*}{ Schizophrenia } & 3.2 & 3.7 & 0.5 & 4.5 & 3.3 & -1.3 \\
\hline & $(1.3)$ & $(1.3)$ & $(1.3)$ & $(1.5)$ & $(2.3)$ & (2.3) \\
\hline \multirow[t]{2}{*}{ Control } & 0.9 & 1.5 & 0.6 & 1.3 & 1.8 & 0.5 \\
\hline & $(1.1)$ & $(1.4)$ & $(1.9)$ & $(1.2)$ & $(1.8)$ & $(1.2)$ \\
\hline
\end{tabular}

Note: $\Delta=$ mean change from baseline to $5 \mathrm{~h}$ (computed as $5 \mathrm{~h}$ minus baseline). Positive values reflect increased symptoms, while negative values reflect decreased symptoms. of group $(\mathrm{F}(1,17)=1.1, p=0.34)$, condition $(\mathrm{F}(1,17)=0.3$, $p=0.58)$, or group $\times$ condition $(\mathrm{F}(1,17)=0.8, p=0.42)$. Mean withdrawal scores were low, suggesting that participants had not experienced significant symptoms. With a possible range of $0-21$, withdrawal levels were: schizophrenics-ATD $M=5.5 \quad(\mathrm{SD}=4.4), \quad$ placebo $\quad M=4.3$ $(\mathrm{SD}=5.4)$; controls - ATD $M=2.3 \quad(\mathrm{SD}=1.5)$, placebo $M=2.5(\mathrm{SD}=1.3)$.

We hypothesized that ATD would produce a pattern of changes in smoking topography in schizophrenics, but not in controls, that indicated decreased smoking, which we expected would occur secondarily to reduced negative symptoms. Change scores from baseline to $5 \mathrm{~h}$ for the topography variables are presented in Table 5. Although the mean values for both groups fell within the ranges reported in prior studies of nonpsychiatric smokers (Kashinsky et al, 1995), the differential variability between schizophrenics and controls in most topography variables required that we normalize their distributions to better satisfy the assumptions of the statistical model. The natural log transformation was used for the variables time to first puff, puff duration, interpuff interval, number of puffs per cigarette, and cigarette duration, while the log odds transformation was used for the variable percentage of cigarette smoked. As described in Mosteller and Tukey (1977), the natural log transformation is very effective at normalizing distributions and reducing heterogeneity of variance for variables that are amounts or counts (ie time to first puff, puff duration, interpuff interval, number of puffs per cigarette, and cigarette duration). Similarly, the log odds transformation is especially useful for percentages (ie percentage of cigarette smoked). Once the variables were transformed, we conducted univariate repeated measures ANCOVA for each topography outcome.

Controlling for cigarette size, there was a statistically significant time $\times$ condition interaction for puff duration, $\mathrm{F}(1,15)=8.81, p=0.01$. Simple main effects analysis revealed that puff duration tended to increase from baseline to $5 \mathrm{~h}$ in the ATD condition, $\mathrm{F}(1,15)=0.56, p=0.47$, but tended to decrease in the placebo condition, $\mathrm{F}(1,15)=3.03$, $p=0.10$. Thus, the significant interaction indicated that the time effect was opposite in direction and differed in size between the two conditions. Figure 1, showing the mean change in puff duration by condition and group, indicates that this topographic sign of increased desire to smoke was altered comparably for schizophrenics and controls. Given that the pattern of mean change scores by condition and group was nearly identical for the transformed and raw values, Figure 1 presents the raw scores for ease of interpretation (although the statistical analyses were carried out on the transformed scale).

We observed a statistically significant time $\times$ condition $\times$ group interaction for cigarette duration controlling for cigarette size, $\mathrm{F}(1,15)=8.81, p=0.049$. Simple interaction analyses revealed a statistically significant time $\times$ condition interaction for schizophrenics, $\mathrm{F}(1,8)=8.08, p=0.02$, but not for controls, $\mathrm{F}(1,6)=0.01, p=0.93$. As Figure 2 shows, schizophrenics, but not controls, exhibited decreased cigarette duration (ie they smoked faster) in response to ATD. Again, given the comparability between the patterns of raw and transformed scores by group and condition, the raw scores are presented for ease of interpretation. The 
Table 5 Mean $( \pm S D)$ Change from Baseline to $5 \mathrm{~h}$ in Smoking Topography as a Function of Psychiatric Diagnosis and Amino-Acid Condition

\begin{tabular}{|c|c|c|c|c|c|c|}
\hline \multirow[b]{3}{*}{ Group } & \multicolumn{6}{|c|}{ Condition } \\
\hline & \multicolumn{3}{|c|}{ Placebo } & \multicolumn{3}{|c|}{ Amino acid } \\
\hline & Baseline & $5 \mathrm{~h}$ & $\Delta$ & Baseline & $5 \mathrm{~h}$ & $\Delta$ \\
\hline \multicolumn{7}{|c|}{ Time to first puff (s) } \\
\hline Schizophrenia & $\begin{array}{c}25.7 \\
(15.7)\end{array}$ & $\begin{array}{c}28.4 \\
(13.2)\end{array}$ & $\begin{array}{r}2.2 \\
(\mid 4.9)\end{array}$ & $\begin{array}{c}25.3 \\
(19.4)\end{array}$ & $\begin{array}{c}22.8 \\
(15.0)\end{array}$ & $\begin{array}{l}-0.9 \\
(27.7)\end{array}$ \\
\hline Control & $\begin{array}{l}15.2 \\
(7.4)\end{array}$ & $\begin{array}{l}23.0 \\
(9.4)\end{array}$ & $\begin{array}{r}7.8 \\
(\mid 1.2)\end{array}$ & $\begin{array}{l}21.0 \\
(5.7)\end{array}$ & $\begin{array}{c}28.3 \\
(11.2)\end{array}$ & $\begin{array}{c}7.3 \\
(9.0)\end{array}$ \\
\hline \multicolumn{7}{|c|}{ Interpuff interval (s) } \\
\hline Schizophrenia & $\begin{array}{c}27.8 \\
(13.6)\end{array}$ & $\begin{array}{c}30.5 \\
(10.8)\end{array}$ & $\begin{array}{c}3.4 \\
(10.3)\end{array}$ & $\begin{array}{c}32.3 \\
(24.9)\end{array}$ & $\begin{array}{c}31.7 \\
(12.7)\end{array}$ & $\begin{array}{l}-1.8 \\
(15.4)\end{array}$ \\
\hline Control & $\begin{array}{c}36.8 \\
(17.2)\end{array}$ & $\begin{array}{c}34.5 \\
(14.8)\end{array}$ & $\begin{array}{r}-2.3 \\
(5.8)\end{array}$ & $\begin{array}{c}38.0 \\
(21.2)\end{array}$ & $\begin{array}{c}37.7 \\
(19.2)\end{array}$ & $\begin{array}{r}-0.3 \\
(7.9)\end{array}$ \\
\hline \multicolumn{7}{|c|}{ Cigarette duration (s) } \\
\hline Schizophrenia & $\begin{array}{c}330.6 \\
(136.6)\end{array}$ & $\begin{array}{c}330.5 \\
(117.6)\end{array}$ & $\begin{array}{c}8.4 \\
(67.1)\end{array}$ & $\begin{array}{c}385.0 \\
(172.3)\end{array}$ & $\begin{array}{c}334.9 \\
(104.1)\end{array}$ & $\begin{array}{r}-45.1 \\
(97.1)\end{array}$ \\
\hline Control & $\begin{array}{l}341.4 \\
(49.3)\end{array}$ & $\begin{array}{l}340.3 \\
(55.4)\end{array}$ & $\begin{array}{l}-1.2 \\
(24.3)\end{array}$ & $\begin{array}{l}358.0 \\
(54.9)\end{array}$ & $\begin{array}{l}358.2 \\
(44.5)\end{array}$ & $\begin{array}{c}0.3 \\
(38.6)\end{array}$ \\
\hline \multicolumn{7}{|l|}{ Puffs per cigarette } \\
\hline Schizophrenia & $\begin{array}{l}13.3 \\
(6.2)\end{array}$ & $\begin{array}{l}\text { II.4 } \\
(4.0)\end{array}$ & $\begin{array}{r}-1.7 \\
(5.1)\end{array}$ & $\begin{array}{l}|4 .| \\
(4.9)\end{array}$ & $\begin{array}{l}\text { II.I } \\
(3.2)\end{array}$ & $\begin{array}{r}-2.5 \\
(2.5)\end{array}$ \\
\hline Control & $\begin{array}{l}10.8 \\
(3.6)\end{array}$ & $\begin{array}{l}\text { II.I } \\
(3.5)\end{array}$ & $\begin{array}{c}0.3 \\
(1.7)\end{array}$ & $\begin{array}{l}11.6 \\
(4.5)\end{array}$ & $\begin{array}{l}\mid 1.1 \\
(3.6)\end{array}$ & $\begin{array}{r}-0.5 \\
(1.6)\end{array}$ \\
\hline \multicolumn{7}{|l|}{ Puff duration (s) } \\
\hline Schizophrenia & $\begin{array}{c}2.3 \\
(1.2)\end{array}$ & $\begin{array}{c}2.3 \\
(1.0)\end{array}$ & $\begin{array}{c}0.0 \\
(0.5)\end{array}$ & $\begin{array}{c}2.2 \\
(0.9)\end{array}$ & $\begin{array}{c}2.4 \\
(1.2)\end{array}$ & $\begin{array}{c}0.3 \\
(0.6)\end{array}$ \\
\hline Control & $\begin{array}{c}2.4 \\
(0.7)\end{array}$ & $\begin{array}{c}2.3 \\
(0.7)\end{array}$ & $\begin{array}{r}-0.2 \\
(0.2)\end{array}$ & $\begin{array}{c}2.2 \\
(0.6)\end{array}$ & $\begin{array}{c}2.4 \\
(1.0)\end{array}$ & $\begin{array}{c}0.2 \\
(0.5)\end{array}$ \\
\hline \multicolumn{7}{|c|}{ \% Cigarette smoked } \\
\hline Schizophrenia & $\begin{array}{l}87.1 \\
(9.7)\end{array}$ & $\begin{array}{l}87.4 \\
(8.2)\end{array}$ & $\begin{array}{c}0.3 \\
(9.5)\end{array}$ & $\begin{array}{l}84.6 \\
(9.4)\end{array}$ & $\begin{array}{c}85.8 \\
(10.4)\end{array}$ & $\begin{array}{c}1.2 \\
(7.3)\end{array}$ \\
\hline Control & $\begin{array}{l}87.1 \\
(7.4)\end{array}$ & $\begin{array}{l}89.0 \\
(4.9)\end{array}$ & $\begin{array}{c}1.9 \\
(5.6)\end{array}$ & $\begin{array}{l}88.3 \\
(7.0)\end{array}$ & $\begin{array}{l}89.0 \\
(5.3)\end{array}$ & $\begin{array}{c}0.8 \\
(5.3)\end{array}$ \\
\hline
\end{tabular}

Note: $\Delta=$ mean change from baseline to $5 \mathrm{~h}$ (computed as $5 \mathrm{~h}$ minus baseline). For time to first puff, interpuff interval, and cigarette duration, positive values reflect decreased desire to smoke. For number of puffs per cigarette, puff duration, and percentage of cigarette smoked, positive values reflect increased desire to smoke.

repeated measures ANCOVAs for the remaining variables (time to first puff, puffs per cigarette, interpuff interval, and percentage of cigarette smoked) revealed no statistically significant main effects or interactions among time, condition, or group (all $p$ 's $>0.05$ ).

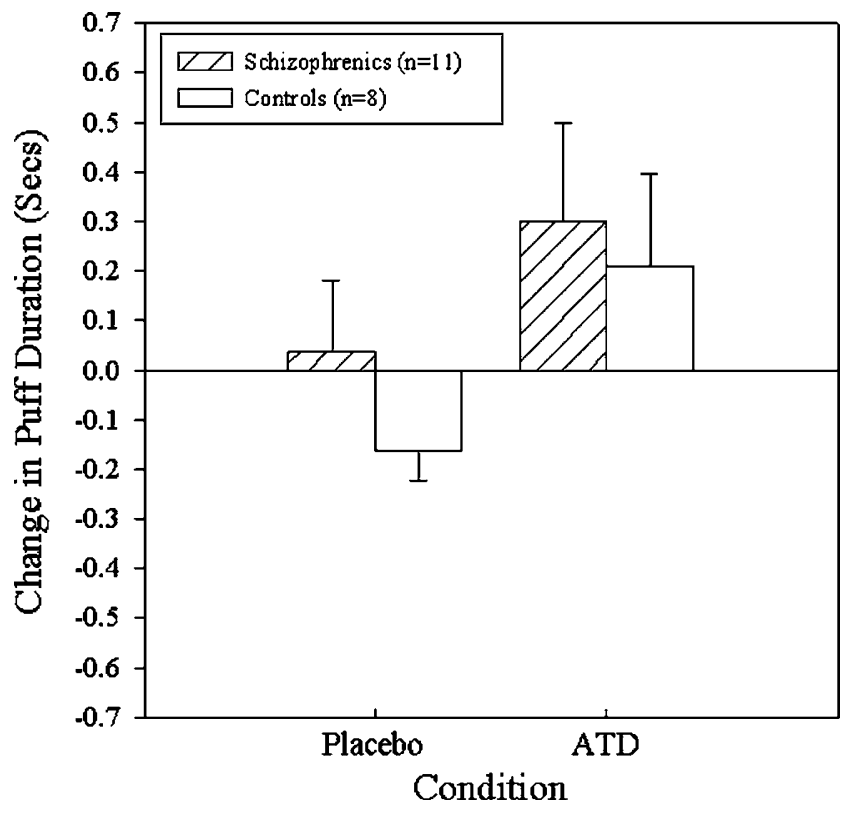

Figure I Change in mean $( \pm S E)$ puff duration from baseline to $5 \mathrm{~h}$ for schizophrenics and controls in response to amino-acid and placebo challenges.

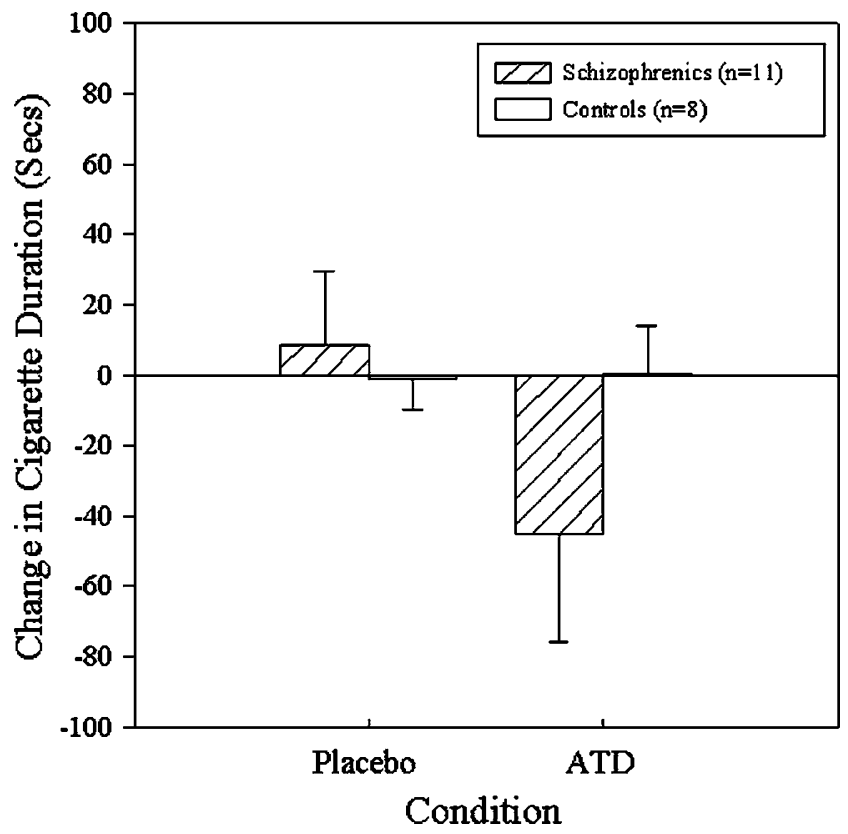

Figure 2 Change in mean ( \pm SE) cigarette duration from baseline to $5 \mathrm{~h}$ for schizophrenics and controls in response to amino-acid and placebo challenges.

\section{DISCUSSION}

The present study was designed to test a self-regulatory model of cigarette smoking in nicotine-dependent schizophrenics by examining whether ATD produced changes in psychopathologic symptoms that, in turn, led to changes in smoking topography. We found that ATD altered smoking topography, despite exerting no influence on psychopathologic symptoms, in minimally deprived schizophrenics and nonpsychiatric controls. Contrary to our expectations, 
however, ATD altered smoking topography in a manner suggesting increased motivation to smoke. While tryptophan depletion influenced the smoking behavior of both groups, there was evidence indicating that schizophrenics were more susceptible than were nonpsychiatric controls.

Prior research has shown that treatment with clozapine leads to reductions in negative symptoms and subsequent smoking (George et al, 1995; McEvoy et al, 1995). However, it has been unclear to what extent acute changes in smoking are mediated indirectly by changes in psychopathologic symptoms vs more directly by changes in serotonin neurotransmission. In other words, it has not been apparent whether schizophrenics treated with atypical antipsychotics smoke less because their negative symptoms improve or, instead, because the drugs' serotonergic antagonism directly reduces their desire to smoke. Our findings suggest that there is a direct effect of serotonin on smoking, as opposed to an indirect effect that is mediated through changes in psychopathologic symptoms. Whereas previous studies of serotonin antagonism mediated via clozapine treatment have shown reduced smoking by schizophrenics (George et al, 1995), we observed the opposite relationship. ATD produced changes in smoking topography that suggested increased, rather than decreased, desire to smoke and these effects were observed not only among schizophrenics but also to a certain degree among nonpsychiatric controls. The differential smoking response when reduced serotonergic function is brought about by ATD $v s$ by atypical antipsychotics may reflect differences in mechanisms of action. Whereas atypical neuroleptics lower serotonergic neurotransmission by blocking postsynaptic serotonin receptor sites (Meltzer et al, 2003), ATD reduces neurotransmission by decreasing the amount of presynaptic serotonin available at serotonin receptor sites (Nishizawa et al, 1997).

Our findings should be viewed in the context of several methodological limitations. First, although our sample size $(N=19)$ was comparable to that of most published ATD studies, our results should be replicated using a larger sample of schizophrenic and nonpsychiatric smokers. Potential differences between schizophrenic and schizoaffective smokers in their smoking and symptom response to trytophan depletion also should be explored. In terms of statistical power, the current sample size only afforded adequate power (ie power of $80 \%$ ) to detect an overall mean difference of 1.4 standard deviation units (ie the effect size) between controls and schizophrenics. Although power was gained because of our repeated measures design, the detectable effect size for the interaction between condition and time was still in the large range. For example, for either the group by condition or group by time interactions, the detectable effect size was approximately 0.9 standard deviation units with $80 \%$ power. Second, because we did not measure nicotine levels before and after the smoking topography sessions, we cannot conclude that the increased smoking after ATD translated to a meaningful increase in nicotine intake. Finally, without more elaborate smoking topography instrumentation, we were unable to assess two characteristics that may be more sensitive to changes in motivation to smoke: volume of smoke inhaled and length of time that the smoke is held in the lungs. Future studies should incorporate mechanical instrumentation that assesses both of these topographical characteristics.

The current study is, to our knowledge, the first to examine the effects of ATD on smoking in minimally deprived smokers. Prior studies have focused on serotonergic involvement in nicotine-withdrawal states (Koob and Le Moal, 2001; Watkins et al, 2000). That work includes a recent study showing that ATD did not exacerbate nicotine withdrawal in nonpsychiatric, nicotine-dependent males who underwent $5 \mathrm{~h}$ of abstinence (Perugini et al, 2003). Our data provide preliminary evidence indicating that serotonin is involved in nicotine dependence and smoking behavior, in that ATD was associated with changes in aspects of cigarette smoking topography. ATD intensified smoking topography in both schizophrenic and nonpsychiatric smokers and did so in the absence of any changes in negative symptoms or depression. It is unclear to us why ATD would be associated with changes in puff duration and cigarette duration, but not with changes in other topographic characteristics, such as number of puffs per cigarette. It is plausible that puff and cigarette duration are more sensitive measures of serotonin-mediated smoking motivation than the other characteristics studied. In general, there has been little consensus among nicotine investigators regarding which topographic measures are most sensitive to changes in smoking motivation (Kashinsky et al, 1995).

Evidence of serotonergic involvement in smoking and nicotine dependence has emerged from smoking cessation treatment studies of agents that enhance serotonergic neurotransmission. L-Tryptophan (Bowen et al, 1991), dexfenfluramine (Spring et al, 1991), paroxetine (Killen et al, 2001), and fluoxetine (Spring et al, 1995; Niaura et al, 2002) all have demonstrated modest, short-term efficacy in enhancing smoking abstinence. Both sertraline (Covey et al, 2002) and paroxetine (Killen et al, 2001) have been shown to reduce cigarette cravings among smokers undergoing intensive smoking treatment. Manipulations of serotonergic function in animals have been found to influence the administration of nicotine, alcohol, and cocaine in a manner consistent with our results (Ciccocioppo, 1999; Olausson et al, 2002).

ATD may have influenced smoking in the current study by increasing the reinforcing value of nicotine. In a prior study (Pingitore et al, 1997), we found that ATD increased the attentional salience of smoking-related cues on a modified Stroop task. In rats, enhancement of serotonergic function has been found to decrease sensitivity to rewarding brain stimulation (Lee and Kornetsky, 1998) and to reverse the reward deficit associated with nicotine withdrawal (Harrison et al, 2001). Evidence of serotonergic modulation of reward and incentive motivational processes in humans was found in a recent ATD study conducted by Rogers et al (2003). In that study of 36 nonpsychiatric individuals, ATD altered decision-making by reducing discrimination between magnitudes of reward on a gambling decisionmaking task.

Contrary to our hypothesis that ATD would influence psychopathologic symptoms among schizophrenics, our results showed that ATD had no effect on negative symptoms or depressive symptoms. This finding is consistent with prior studies of ATD in schizophrenics, 
which have failed to observe effects on negative symptoms or depression among clozapine-treated (George et al, 2002) or haloperidol-treated patients (Sharma et al, 1997; Golightly et al, 2001). Our results are consistent with George et al's (2002) interpretation that acute reduction in the presynaptic availability of serotonin produced by tryptophan depletion is insufficient to affect symptomatology in schizophrenics. However, serotonergic changes brought about by ATD do alter smoking topography in a manner suggestive of increased craving.

\section{ACKNOWLEDGEMENTS}

This study was funded by an NRSA Individual Predoctoral Fellowship (F31 DA05854) from the National Institute on Drug Abuse awarded to Brian Hitsman, PhD. Additional research support was provided by a Mentored Clinical Scientist Development Award (K08 DA017145) to Brian Hitsman, PhD, a National Heart Lung and Blood Institute grant (HL59348) and a VA Merit Review award to Bonnie Spring, $\mathrm{PhD}$, an American Cancer Society grant awarded to Regina Pingitore, $\mathrm{PhD}$, and by the National Cancer Institute, Transdisciplinary Tobacco Use Research Center Grant, P50 CA84719. This study was performed in partial fulfillment of the clinical psychology doctoral degree of Brian Hitsman, $\mathrm{PhD}$, under the direction of Bonnie Spring, $\mathrm{PhD}$, while at Finch University of Health Sciences/The Chicago Medical School. We thank Dianna Gunnarsdottir, PhD, Michele Pergadia, PhD, Donna Delaney, Edward Fink, and Elizabeth Rebocho for their assistance with participant screening and testing. An earlier version of this report was presented at the Eighth Annual Meeting of the Society for Research on Nicotine and Tobacco, Savannah, GA, February 2002.

\section{REFERENCES}

American Psychiatric Association (1994). Diagnostic and Statistical Manual of Mental Disorders, 4th edn. Author: Washington, DC.

Beck AT, Ward CH, Mendelson M, Mock J, Erbaugh J (1961). An inventory for measuring depression. Arch Gen Psychiatry 4: 561-571.

Bowen DJ, Spring B, Fox E (1991). Tryptophan and high carbohydrate diets as adjuncts to smoking cessation therapy. J Behav Med 41: 97-110.

Ciccocioppo R (1999). The role of serotonin in craving: From basic research to human studies. Alcohol Alcoholism 34: 244-253.

Covey LS, Glassman AH, Stetner F, Rivelli S, Stage K (2002). A randomized trial of sertraline as a cessation aid for smokers with a history of major depression. Am J Psychiatry 159: 1731-1737.

Dalack GW, Healy DJ, Meador-Woodruff JH (1998). Nicotine dependence in schizophrenia: clinical phenomenon and laboratory findings. Am J Psychiatry 155: 1490-1501.

Davidson D, Paifai T, Bird C, Swift R (1999). Effects of naltrexone on alcohol self administration in heavy drinkers. Alcoholism: Clin Exp Res 20: 732-739.

De Leon J, Dadvand M, Canuso C, White AO, Stanilla JK, Simpson GM (1995). Schizophrenia and smoking: an epidemiological survey in a state hospital. Am J Psychiatry 152: 453-455.

Delgado PL, Charney DS, Price LH, Aghajanian GK, Landis H, Heninger GR (1990). Serotonin function and the mechanism of antidepressant action. Arch Gen Psychiatry 47: 411-418.
Delgado PL, Price LH, Miller HL, Salomon RM, Licinio J, Krystal $\mathrm{JH}$ et al (1991). Rapid serotonin depletion as a provocative challenge test for patients with major depression: relevance to antidepressant action and the neurobiology of depression. Psychopharmacol Bull 27: 321-330.

Fagerstrom KO (1978). Measuring degree of physical dependence to tobacco smoking with reference to individualization of treatment. Addict Behav 3: 235-241.

George TP, Sernyak MJ, Ziedonis DM, Woods SW (1995). Effects of clozapine on smoking in chronic schizophrenic outpatients. J Clin Psychiatry 56: 344-346.

George TP, Ziedonis DM, Feingold A, Pepper WT, Satterburg CA, Winkel J et al (2000). Nicotine transdermal patch and atypical antipsychotic medications for smoking cessation in schizophrenia. Am J Psychiatry 157: 1835-1842.

George TP, Potenza MN, Degan K, Sernyak MJ, McDougle CJ, Woods SW (2002). Acute tryptophan depletion in clozapineresponsive chronic schizophrenic patients. Arch Gen Psychiatry 59: 291-292.

Golightly KL, Lloyd JA, Hobson JE, Gallagher P, Mercer G, Young AH (2001). Acute tryptophan depletion in schizophrenia. Psychol Med 31: 75-84.

Hamilton MA (1967). Development of a rating scale for primary depressive illness. Br J Soc Clin Psychol 6: 278-296.

Harrison AA, Liem YTB, Markou A (2001). Fluoxetine combined with a serotonin-1a receptor antagonist reversed reward deficits observed during nicotine and amphetamine withdrawal in rats. Neuropsychopharmacology 25: 55-71.

Hughes JR, Hatsukami DK (1986). Signs and symptoms of tobacco withdrawal. Arch Gen Psychiatry 43: 289-294.

Hughes JR, Hatsukami DK, Mitchell JE, Dahlgren LA (1986). Prevalence of smoking among psychiatric outpatients. Am J Psychiatry 143: 993-997.

Hughes JR, Howard TS (1997). Nicotine and caffeine use as confounds in psychiatric studies. Biol Psychiatry 42: 1184-1185.

Kashinsky W, Collins BN, Brandon TH (1995). A telemetric device for measuring smoking topography. Behav Res Methods Instrum Comput 27: 375-378.

Kay SR, Opler LA, Fiszbein A (1987). Positive and Negative Syndrome Scale (PANSS) Rating Manual. Social and Behavioral Sciences Documents: San Rafael, CA.

Killen JD, Fortmann SP, Schatzberg AF, Hayward C, Sussman L, Rothman $\mathrm{M}$ et al (2001). Nicotine patch and paroxetine for smoking cessation. J Consult Clin Psychol 68: 883-889.

Koob GF, Le Moal M (2001). Drug addiction, dysregulation of reward, and allostasis. Neuropsychopharmacology 24: 97-129.

Lee K, Kornetsky C (1998). Acute and chronic fluoxetine treatment decreases the sensitivity of rats to rewarding brain stimulation. Pharmacol Biochem Behav 60: 539-544.

Lieberman JA, Mailman RB, Duncan G, Sikich L, Chakos M, Nichols DE et al (1998). Serotonergic basis of antipsychotic drug effects in schizophrenia. Biol Psychiatry 44: 1099-1117.

McChargue DE, Gulliver SB, Hitsman B (2002). Would smokers with schizophrenia benefit from a more flexible approach to smoking treatment? Addiction 97: 785-793.

McEvoy JP, Freudenreich O, McGee M, VanderZwaag C, Levin ED, Rose JE (1995). Clozapine decreases smoking in patients with chronic schizophrenia. Biol Psychiatry 37: 550-552.

Meltzer HY, Li Z, Kaneda Y, Ichikawa J (2003). Serotonin receptors: their key role in drugs to treat schizophrenia. Progr Neuro-Psychopharmacol Biol Psychiatry 27: 1159-1172.

Mosteller F, Tukey J (1977). Data Analysis and Regression: A Second Course in Statistics. Addison-Wesley: Reading, MA.

Niaura R, Spring B, Borrelli B, Hedeker D, Goldstein MG, Keuthen $\mathrm{N}$ et al (2002). Multicenter trial of fluoxetine as an adjunct to behavioral treatment for smoking cessation: different missing data assumptions yield differing outcomes. J Consult Clin Psychol 70: 887-896. 
Nishizawa S, Benkelfat C, Young SN, Leyton M, Mzengeza S, De Montigny C et al (1997). Differences between males and females in rates of serotonin synthesis in human brain. Proc Natl Acad Sci 94: 5308-5313.

O’Farrell T, Connors GJ, Upper D (1983). Addictive behaviors among hospitalized schizophrenic patients. Addict Behav 8: 329-333.

Olausson P, Engel JA, Soderpalm B (2002). Involvement of serotonin in nicotine dependence: processes relevant to positive and negative regulation of drug intake. Pharmacol Biochem Behav 71: 757-771.

Olincy A, Young DA, Freedman R (1997). Increased levels of the nicotine metabolite cotinine in schizophrenic smokers compared to other smokers. Biol Psychiatry 42: 1-5.

Pergadia M, Spring B, Konopka LM, Twardowska B, Shirazi P, Crayton JW (2004). Double-blind controlled trial of the effect of tryptophan depletion on depression and cerebral blood flow in smokers. Addict Behav 29: 665-671.

Perugini M, Mahoney C, Ilivitsky V, Young SN, Knott V (2003). Effects of tryptophan depletion on acute smoking abstinence symptoms and the acute smoking response. Pharmacol Biochem Behav 74: 513-522.

Pingitore R, Spring B, Hitsman B, Kohlbeck P (1997). Tryptophan depletion heightens the salience of cues associated with cigarette cravings. Ann Behav Med 19(Suppl): SO66.

Renkin H, Hodgson R, Stockwell T (1979). The concept of craving and its measurement. Behav Res Ther 17: 389-396.

Rogers RD, Tunbridge EM, Bhagwager Z, Drevets WC, Sahakian BJ, Carter CS (2003). Tryptophan depletion alters the decision- making of healthy volunteers through altered processing of reward cues. Neuropsychopharmacology 28: 153-162.

Sharma RP, Shapiro LE, Kamath SK, Soll EA, Watanabe MD, Davis JM (1997). Acute dietary tryptophan depletion: effects on schizophrenic positive and negative symptoms. Neuropsychobiology 35: 5-10.

Spring B, Pingitore R, Kessler K, Hitsman B, Gunnarsdottir D, Corsica J et al (1997). Parallel depressive response to serotonergic challenge and nicotine withdrawal. In: Spring B (Chair). Mechanisms Linking Nicotine Dependence and Psychopathology. Symposium conducted at the Eighteenth Annual Meeting of the Society of Behavioral Medicine, San Francisco, CA.

Spring B, Wurtman J, Gleason R, Wurtman R, Kessler K (1991). Weight gain and withdrawal symptoms after smoking cessation: A preventive intervention using D-fenfluramine. Health Psychol 10: $216-223$.

Spring B, Wurtman J, Wurtman R, El-Khoury A, Goldberg $\mathrm{H}$, McDermott $J$ et al (1995). Efficacies of dexfenfluramine and fluoxetine in preventing weight gain after smoking cessation. Am J Clin Nutr 62: 1181-1187.

Watkins SS, Koob GF, Markou A (2000). Neural mechanisms underlying nicotine addiction: acute positive reinforcement and withdrawal. Nicotine Tobacco Res 2: 19-37.

Williams JBW, Gibbon M, First MB, Spitzer RL, Davies M, Borus J et al (1992). The Structured Clinical Interview for the DSM-III-R (SCID). II. Multisite test-retest reliability. Arch Gen Psychiatry 49: 630-636. 